geal echocardiography score, before and after repair. The data again demonstrate the importance of placing an annuloplasty ring for every mitral valve repair ${ }^{11,12}$ as approximately one fourth of the patients who underwent a reoperation had no ring placed at the initial operation even though the valve was competent at that time. The incidence of repair failure was $7 \%$ in those with anterior leaflet disease and again documents the fact that anterior leaflet prolapse is more difficult to treat, which is documented in every series of mitral valve repairs. ${ }^{13,14}$ No patient was left with more than $2+\mathrm{MR}$, but many of these did fall into the reoperation group due to the causes outlined in Table 5 .

Over the 6-year period operative techniques have changed. Currently, we use a lower ministernotomy and the standard left atrial approach. No patient had to convert to a full sternotomy. Other minimally invasive approaches used and reported on recently with success are the port-access technique ${ }^{15}$ endscopically guided techniques, ${ }^{16}$ and the robotic assisted mitral valve repair surgery. ${ }^{17}$ All these studies similarly show low mortality and good medium-term results.

The present study documents the safety of minimally invasive mitral valve repair surgery in 358 patients. The low incidence of homologous blood utilization and the requirement for post-hospital rehabilitation confirms data from previous studies. We also document that the reparability of the mitral valve is quite high and the probability of valve failure after the learning curve is overcome is reasonably low. We believe this safe and efficacious operation will do much to lower the threshold for the early referral of patients undergoing mitral valve surgery.

\section{Limitations of the Study}

The major limitation of this study is that it is a retrospective study. Although all of the cardiac surgery data are collected from the Brigham Cardiac Surgical database to update the progress of patients, particularly for valve repair, patients had to be retrospectively contacted. We had a low rate of patients lost to follow-up (1.5\%). To truly gauge the effectiveness of the operation one would have to do a prospective randomized study, but we do not think this is feasible.

The second limitation is that we do not have consistent universal long-term echocardiographic data on every patient. We have data on approximately $75 \%$ of such patients and the results are quite good.

\section{References}

1. Cohn LH, Adams DH, Couper GS, et al. Minimally invasive cardiac valve surgery improves patient satisfaction while reducing costs of cardiac valve replacement and repair. Ann Surg. 1997;226:4 421-8.

2. Cosgrove DM, Sabik JF, Navia JL. Minimally invasive valve operations. Ann Thorac Surg. 1998;65:1535-8.

3. Doty D, DiRusso G, Doty J, et al. Full-spectrum cardiac surgery through a minimal incision: mini-sternotomy (lower half) technique. Ann Thorac Surg. 1998;65:56970.
4. Gundry SR, Shattuck OH, Razzouk AJ, et al. Facile minimally invasive cardiac surgery via ministernotomy. Ann Thorac Surg. 1998;65: 1100-4.

5. Carpentier A, Loulmet D, Carpentier A, et al. Chirurgie a coeur par video-chirurgie et mini-thoracotomie: premier cas (valvuloplastie mitrale) opere succes. Comptes Rendus De L'Academie des Sciences: Sciences de la Vie. 1996;319:219-23.

6. Navia JL, Cosgrove DM. Minimally invasive mitral valve operations. Ann Thorac Surg. 1996;62:1542-4.

7. Adams DH, Roborough DM, Couper GS, Cohn LH. Cardiac valve surgery through small access incisions is safe and associated with improved patient satisfaction. J Am Coll Cardiol.. 1998;31(suppl A): 68.

8. Mohr FW, Falk V, Diegler A, et al. Minimally invasive port-access mitral valve surgery. J Thorac Cardiovasc Surg. 1997;113:413-4.

9. Loulmet DF, Carpentier A, Cho PW, et al. Less invasive techniques for mitral valve surgery. J Thorac Cardiovasc Surg. 1998;115:567-74.

10. Chitwood WR Jr, Elbeery JR, Chapman WH, et al. Video-assisted minimally invasive mitral valve surgery: the "micro-mitral" operation. J Thorac Cardiovasc Surg. 1997;113:413-4.

11. Carpentier A. Cardiac valve surgery: the "French correction." J Thorac Cardiovasc Surg. 1983;86:323-47.

12. Cohn LH, Couper GS, Aranki SF, Rizzo RJ, Kinchla NM, Collins JJ Jr. Long-term results of mitral valve reconstruction for regurgitation of the myxomatous mitral valve. J Thorac Cadiovasc Surg. 1994;107: 143-51.

13. Braunberger E, Deloche A, Berrebi A, et al. Very long-term results (more than 20 years) of valve repair with Carpentier's techniques in non-rheumatic mitral valve insufficiency. Circulation. 2001; 104(Suppl):I8-11.

14. Mohty D, Orszulak TA, Schaff HV, Avierinos JF, Tajik JA, EnriquezSarano M. Very long-term survival and durability of mitral valve repair for mitral valve prolapse. Circulation. 2001;104(Suppl):I1-7.

15. Grossi EA, Galloway AC, Rebakove GH, et al. Impact of minimally invasive valvular heart surgery: a case control study. Ann Thorac Surg. 2001;71:807-10.

16. Casselman FP, Van Slycke S, Dom H, Lambrechts DL, Vermeulen Y, Vanermen H. Totally endoscopic mitral valve repair: feasible, reproducible, and durable. J Thorac Cardiovasc Surg. 2002;125:273-82.

17. Felger JE, Nifong LW, Chitwood WR Jr. The evolution of and early experience with robot-assisted mitral valve surgery. Surg Laparosc Endosc Percutan Tech. 2002;12:58-63.

\section{Discussion}

Dr Scot Merrick (San Francisco, Calif). Anybody who does mitral valve surgery is well aware of the exceptional contributions of your group, particularly Dr Cohn, over the past several decades in the advancement of mitral valve surgery, and I think this paper is a clear reflection of what you have accomplished.

Mitral valve surgery through small incisions is clearly here to stay. However, can you do the same techniques through a small incision that you can through regular incision? Are they safe? Will you get the same long-term results? I think you have gone a long way to answer some of these questions.

I do have a couple of questions for you. One relates to patient selection. Most of your patients were relatively young, had very little comorbidity, had myxomatous disease and mostly of the posterior leaflet. How did you determine what type of incision to make in this group of patients? I notice that you did do 51 procedures through a standard incision. Were there criteria that you used to select out these patients for a large incision, which would make you avoid doing a small incision?

Dr Greelish. That is an insightful question. This patient population does represent a younger population with less comorbidity, but that in general reflects our philosophy at the Brigham. My 
conclusion slide indicates that we believe these patients can come to surgery when they are healthier, when they are younger, before undergoing some of the changes that are a result of MR. That is a reflection of the overall philosophy in the hospital, of the cardiologists as well as the surgeons.

Regarding the choice of incision, all patients are considered for minimally invasive repair; however, it is surgeon's preference as to what they undergo. The majority of these operations were performed by one surgeon, Dr Cohn, and I would say that all patients are approached minimally invasively from the start. In Dr Cohn's personal series, he has had no conversions to my knowledge.

Dr Merrick. Anterior leaflet repairs are always more difficult, and the long-term outcome is probably not as good in general. If you believe Pat Cochran's data on the tension of the anterior leaflet then you could surmise that resections of the anterior leaflet will more likely fail. I noticed in some of Dr Cohn's previous discussions at the AATS that he did not do anterior leaflet resections and favored PTFE cord replacement and always inserting rings. Why did you change that philosophy in this group of patients?

Dr Greelish. A very small minority of the patients-5, if I am not mistaken - underwent anterior leaflet resection. The majority of the patients who had anterior leaflet disease had other techniques used, for example, commissuroplasty or PTFE neochordae to deal with the diseased anterior leaflet. I would say that those anterior leaflet resections were done early on in the series and currently the standard way to deal with anterior leaflet pathology is to perform a commissuroplasty and/or PTFE neochordae.

Dr Merrick. Are you saying that you did not find any problems with exposure of the subvalvular area for anterior leaflet repairs in this series?

Dr Greelish. I would say the exposure is really very good through this technique. As I have told some of the other people I have helped train in this technique, it is not the size of the incision but rather where the incision is placed. With the instruments that we use and with an appropriately placed incision, I think that the exposure is identical.

Dr Merrick. Let me change gears a little bit. All the hype about off-pump surgery for coronary disease relates around modification of the systemic inflammatory response and how that translates into improved morbidity and faster recovery. Since that is not applicable to this group of patients, do you think that length of the incision is really the determinant of why these patients do better and get out of the hospital faster?

Dr Greelish. That being the primary thing that we do differently, I do not know what else to attribute it to. I can tell you from a sort of common sense standpoint it would appear at least that a smaller incision means less trauma which means less exposed surfaces to bleed and less opportunity for infection. I think our results are consistent with that.

Dr Merrick. It would be nice to know some of the long-term data on your echocardiographic assessment of MR. I am particularly interested in the group of patients that had the transseptal approach to mitral valve exposure, as to whether or not they had any long-term sinus node dysfunction or atrial flutter.

Dr Greelish. The echocardiographic follow-up in these patients is about $75 \%$. Due to the nature of our patient population, it is very difficult to get that although those results are pretty much consistent with the immediate postoperative intraoperative echo- cardiographic results. The series has a very small rate of heart block. I think one of the reasons for that is something that Dr Cohn is very adamant about in the operating room: When you make the septal incision that you make it up toward the SVC rather than up toward the atrial appendage. In that way you avoid the conducted tissue in that region.

Dr Merrick. I think this is a great series. Your conclusion in my opinion should be that we should encourage the cardiologists to refer patients earlier. It does not really matter how you make the incision. The patients do better when they are referred early. Their outcomes are better. I think this is clearly one of the landmark series in small incision mitral series, and I congratulate you on that.

Dr Edward Verrier (Seattle, Wash). The title of the paper says, "Early and Late Results of Minimally Invasive Mitral Valve Surgery Suggests Earlier Operations ...." The Mayo Clinic a number of years ago suggested that the transition from replacement to repair was really a critical determinant of moving the cardiologists toward an earlier position by intervention. What would be the line of argument now that simply by a smaller incision we ought to consider earlier intervention?

Dr Cohn is quite known for his technical prowess, as are other of our leaders who profess the superiority of this early repair approach. How many of the cases did the residents do versus Dr Cohn, because in an educational environment the size of the incision does have an impact potentially on exposure and the ability to teach it? I would be curious about the resident's ability to learn the technique in a regular residency.

My third question has to do with air. Have you learned over the years any specific techniques through the small incision of modifying the ability to get air out of these left ventricles postoperatively?

Dr Greelish. Thank you for those questions. Your first question concerned whether the smaller incision really warrants earlier intervention. I do not know that you can necessarily draw that conclusion, although I will say that the morbidity and mortality is quite low with this technique. That being the case, why not do the operation through this technique? I think that the overall concept of moving toward mitral valve repair is one that you can make regardless of whether you make a small incision or a large incision. This just provides more evidence to that fact and evidence that the operation can be done with a smaller incision with lower morbidity and mortality, and because of that lower morbidity and mortality may actually provide additional evidence for repair.

Regarding your second question, yesterday morning I had the pleasure of presenting my own personal experience at the Brigham $\&$ Women's Hospital to our division. Of the 362 patients over the course of 3 years, I personally have set up $10 \%$ of those. So $10 \%$ of those-all of the operations are actually set up by the resident. The number that is performed as surgeon is $10 \%$ in my case. I cannot speak for the other residents, so I would say approximately half of the operations that residents scrub on they do as surgeon. As you well know, it takes a number of operations before you feel comfortable with the technique, but I would say about half of the operations are done with the resident as the surgeon.

Our current technique for de-airing consists of placing a deairing needle in the aortic root, taking venous return and agitating. 
Dr Hillel Laks (Los Angeles, Calif). One of the proposed advantages of the minimally invasive approach is also cosmetic, and the right minithoracotomy is particularly cosmetically advantageous for a younger woman. In your institution, have you used that approach as well, or do you only use the lower sternotomy?

Dr Greelish. We currently use the midline ministernotomy and we experimented with the right thoracotomy early on. We use the latter primarily for the robotic repair cases.

Dr Laks. Why was that abandoned?

Dr Greelish. The cosmetic reason was one reason. The cosmetic result was not satisfactory in those patients and in the patients who underwent a parasternal incision. There were a number of patients early on who had some lung herniation in the parasternal incision. We then dealt with that by placing mesh, PTFE or Marlex, to avoid that in the parasternal incisions.

Dr Laks. I was talking about the intercostal approach.

Dr Greelish. That approach as well can be used, but we prefer the minimally invasive approach. We find that if you center it between the woman's breasts it can be hidden quite easily and readily.
Dr Alfredo Trento (Los Angeles, Calif). You used a median sternotomy in a group of patients. Do you have the length of stay of that group of patients as compared to the partial sternotomy patients?

You described the use of homologous blood. The usage I think was $24 \%$ of the patients. How many patients received autologous blood?

Dr Greelish. Probably another $10 \%$ received autologous blood, although that is obviously their own and the risks are somewhat lower due to that fact. The rate of homologous blood transfusion was only $24 \%$ I believe.

We did not evaluate the length of stay in this series. However, in Dr Cohn's original series presented at the American Surgical Association meeting, we did look at that. I do not have the exact number for you, but I can tell you that the length of stay after a ministernotomy is significantly shorter than after a full sternotomy. That was also found in a follow-up series that was performed Adams and associates, which was presented in the Journal of the American College of Cardiology. 